PRODUTO \& PRODUÇÃO, vol. 22, n.2, p.1-18. 2021*

\title{
Avaliação de desempenho de smart home: um mapa da literatura
}

\section{Smart Home Performance Evaluation: a literature map}

\author{
Débora Rosa Nascimento \\ Instituto Federal de Minas Gerais - IFMG \\ email: debora.nascimento@ifmg.edu.br
}

\section{Sandra Rolim Esslin}

Universidade Federal de Santa Catarina - IFMG - Brasil

email:sensslin@gmail.com

\begin{abstract}
Resumo
O uso de smart home é um tema emergente que demanda criação de estratégias para atender às necessidades dos usuários. As ferramentas da avaliação de desempenho podem ser um auxílio nesse processo. Assim, o objetivo deste artigo é identificar as características dos estudos na área de avaliação de desempenho de smart home. Foi utilizado o ProKnow-C como instrumento de intervenção metodológica que orientou a seleção de 30 artigos selecionados nas bases de dados Scopus e Web of Science. Com base no portfólio bibliográfico selecionado: (i) a análise bibliométrica permitiu a constatação da existência de discussões de características emergentes em três períodos temporais e (ii) os mapas da literatura construídos sintetizam a abordagem de smart home em termos da tecnologia, serviços e usuários. A análise sistemática possibilitou a direção de novos estudos para investigar a lacuna existente na literatura relacionada à gestão da avaliação de desempenho de smart home.
\end{abstract}

Palavras-chave: Avaliação de Desempenho; Smart Home; Mapa da Literatura

\section{Abstract}

${ }^{*}$ RECEBIDO EM 27/08/2020. ACEITO EM 11/11/2020. 
The usage of smart home is an emergent matter that demands the creation strategies for supply for the users' needs. The performance evaluation tools help this process. Thus, this article's aim is to identify the characteristics of studies in the area of performance evaluation of smart home. We used the ProKnow-C as the instrument of methodological intervention that guided the 30-article selection from the Scopus and Web of Science database. Based on the bibliographic portfolio selected: (i) the bibliometrics analysis allowed the finding of the existence of discussions of emergent characteristics in three temporal periods and (ii) the built maps of literature synthesize the approach of smart home in terms of technology, services and users. The systematic analysis enables the direction of new studies to investigate the lack in the literature related to the management of smart home performance evaluation.

Keywords: Performance evaluation; Smart home; Map of literature.

\section{Introdução.}

O crescente uso de tecnologias de comunicação e informação, com o apoio da Internet da Coisas (Internet of Things - IoT) permitiu o desenvolvimento da smart home (LANGHAMMER; KAYS, 2012; KANG; LIN et. al., 2016; LIN; ZHANG, 2018). No mercado da construção civil, os prédios inteligentes surgiram como uma vantagem competitiva tanto na otimização de recursos energéticos para os construtores, quanto na diferenciação em termos de conforto para os usuários, por meio da implantação da inteligência nos edifícios (CHEN et. al., 2006; KATZ; SKOPEK, 2009). Essa vantagem competitiva despertou interesse por parte de construtores e usuários de residências na busca de conforto e bem-estar por meio da implantação de novas tecnologias.

As organizações, ao introduzir o conceito de smart home em suas estratégias, perceberam a necessidade de identificar meios de avaliar o desempenho de seus serviços e produtos para que o diferencial chegasse até o cliente e os seus recursos fossem otimizados. Para facilitar a implementação das estratégias e melhorar o desempenho das empresas, os sistemas de avaliação de desempenho são constantemente recomendados (MELNYK et. al., 2013). A natureza dos serviços e produtos de smart home gera a necessidade de monitoramento durante o uso da residência que se torna mais eficiente com diagnósticos obtidos por meio da Avaliação de Desempenho (AD). As empresas estão cada vez mais sob pressão para criar valor para seus stakeholders. Em vista disso, as práticas de $\mathrm{AD}$ podem contribuir para essa tarefa (FRANCO-SANTOS; LUCIANETTI; BOURNE, 2012).

Práticas de Avaliação e Gerenciamento de Desempenho são comuns em todos os setores, tanto da indústria, quanto do comércio (BITITCI et al., 2012). A avaliação de desempenho é um tema de pesquisa que permeia várias áreas de conhecimento, inclusive as áreas emergentes. Diante desse contexto, surge a seguinte pergunta de pesquisa: Como a avaliação de desempenho está apresentada em relação a smart home na literatura atual?

O objetivo deste trabalho é identificar as características dos estudos na área de avaliação de desempenho de smart home, por meio de um fragmento da literatura, obtido pela busca em duas bases de dados específicas e em determinado período o que delimita este trabalho. A ferramenta de intervenção usada para alcançar esse objetivo é o ProKnow-C (LACERDA; ENSSLIN; ENSSLIN, 2012; DUTRA et al., 2015; THIEL; ENSSLIN; ENSSLIN, 2017).

A contribuição deste artigo pode ser vista para o meio acadêmico e para aplicações práticas. Para a academia, este artigo enriquece a literatura atual por meio de uma revisão sistemática específica sobre a smart home à luz da avaliação de desempenho. Enriquecimento este que trata sobre as contribuições da avaliação de desempenho aplicadas à smart home. Identificando quais métodos e/ou ferramentas já vem sendo utilizadas para avaliar e melhorar o desempenho de tecnologias e suas interações com o meio ambiente e o usuário em uma smart home. 
Para aplicações práticas, as empresas relacionadas com as tecnologias de smart home, sejam elas construtoras, empresas de tecnologia de informação, empresas de automação, entre outras, podem obter neste trabalho direcionamentos estratégicos a fim de melhorar o desempenho de uma smart home.

Este estudo foi feito com base em um fragmento extraído da literatura com condições específicas de coletas de dados, que gerou um portfólio reduzido de artigos. Essa situação limita o presente estudo.

\section{Métodos.}

A seção metodológica deste trabalho está dividida em três tópicos. O primeiro apresenta o instrumento de intervenção usado e suas etapas, Knowledge Development Process-Constructivist (ProKnow-C). O segundo tópico descreve os procedimentos usados no processo de coleta de dados para realização desta pesquisa, com base em uma das etapas do ProKnow-C. O terceiro tópico descreve os procedimentos usados para análise dos dados.

\subsection{Instrumento de intervenção.}

Este trabalho utilizou o Knowledge Development Process-Constructivist, (ProKnow-C) (Figura 1), como instrumento de intervenção metodológica (ENSSLIN; ENSSLIN; DUTRA, 2019). Esse instrumento é norteado pela abordagem construtivista que permite gerar conhecimento sobre um tema de pesquisa com base na literatura selecionada. Essa característica torna o instrumento adequado para atingir o objetivo deste trabalho.

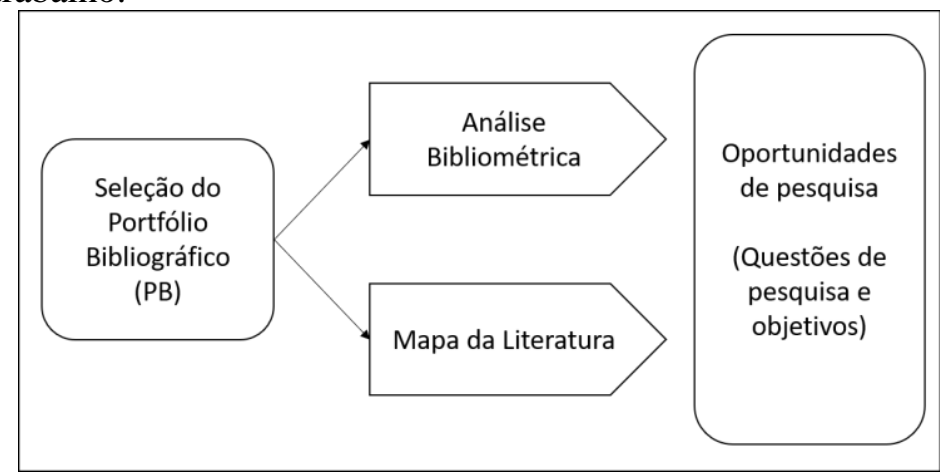

Figura 1 - Instrumento de intervenção - ProKnow-C

A Figura 1 apresenta, de forma geral, as etapas de (i) Seleção do portfólio bibliográfico, (ii) Análise bibliométrica, (iii) Mapa da literatura, e (iv) Pergunta de pesquisa. Todas essas etapas são compostas por subetapas. Neste trabalho, as quatro etapas foram desenvolvidas.

2.2. Procedimentos para coleta dos dados: seleção do portfólio bibliográfico. 
A Figura 2 apresenta o resumo da etapa da seleção do Portfólio Bibliográfico (PB). Na sequência, os procedimentos realizados nas subetapas, seleção do banco de artigos bruto e filtragem do banco de dados, são descritos (LACERDA; ENSSLIN; ENSSLIN, 2012; DUTRA et al., 2015; THIEL; ENSSLIN; ENSSLIN, 2017; STAEDELE; ENSSLIN; FORCELLINI, 2019).

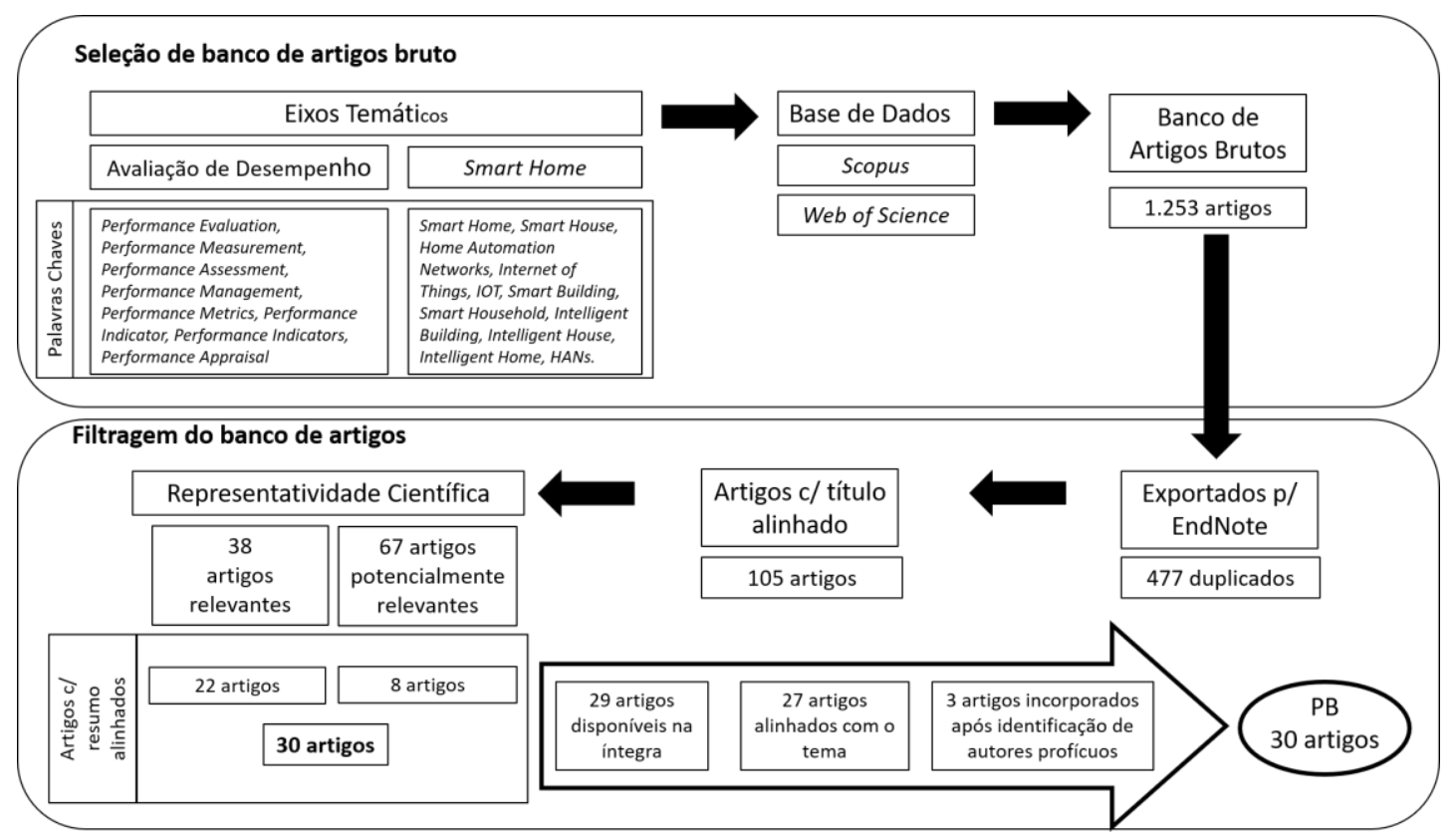

Figura 2 - Seleção do PB, conforme ProKnow-C

Para a seleção do banco de artigos bruto é necessário definir os eixos temáticos de pesquisa. Como o objetivo deste artigo é identificar as características dos estudos na área de avaliação de desempenho de smart home tem-se estes dois eixos: avaliação de desempenho e smart home. Para a avaliação de desempenho, definiram-se as seguintes palavras-chave: performance evaluation, performance measurement, performance assessment, performance management, performance metrics, performance indicator, performance indicators e performance appraisal. Para o eixo smart home, foram definidos os termos smart home, smart house, home automation networks, internet of things, IoT, smart building, smart household, intelligent building, intelligent house, intelligent home e HANs, como palavras-chave.

As bases de dados usadas para pesquisa foram Scopus e Web of Science. Foram ainda consideradas apenas publicações em periódicos científicos, em inglês, e publicadas até 2020. A pesquisa com as palavras-chave foi feita nos campos título, resumo e palavras-chave dos artigos publicados nas bases de dados. O período de realização da pesquisa nas bases foi de 17 de outubro de 2019 a 23 de outubro de 2019.

Foram encontrados 1.253 artigos com base nas delimitações desta pesquisa. O teste de aderência das palavras-chave foi feito e estas permaneceram as mesmas, finalizando 1.253 artigos no banco de artigos bruto selecionado.

A subetapa filtragem do banco de artigos teve início com 1.253 artigos. Todos foram exportados para o software EndNote e foram excluídas 290 publicações duplicadas diretamente pelo software e 187 publicações em conferências, livros e capítulos de livros, obtendo, ao final dessa primeira filtragem, 776 artigos. Estes foram examinados conforme o título, e, nos casos em que os títulos dos artigos estavam claramente desalinhados, foram excluídos 671 por não contribuírem para esta pesquisa, permanecendo 105 artigos.

É necessária a identificação da representatividade científica por meio do número de citações de cada artigo. Nesta pesquisa, dos 105 artigos, os 38 mais citados representam 91,5\% do número total de 
citações, formando um repositório cientificamente relevante; e os 67 artigos restantes apresentam menos de 10 citações, formando um repositório com artigos potencialmente relevantes. Dos 38 artigos não repetidos, com título alinhado e com reconhecimento científico, 22 deles possuem o resumo alinhado com o tema. Esses 22 artigos foram escritos por um total de 85 autores, formando o Banco de Autores (BA). Para garantir a representatividade científica, utilizou-se o repositório de 67 artigos não repetidos, com título alinhado e com potencial reconhecimento científico para filtragem. Desse conjunto foram separados os artigos mais recentes (publicados em 2017, 2018 e 2019/2020): 55 artigos. Do restante, foram separados os artigos em que pelo menos um dos autores era integrante do BA, e, nesse caso, apenas um artigo foi selecionado. Dos 56 artigos selecionados com potencial relevância científica, oito apresentaram resumo alinhado com o tema.

Ao final dessa filtragem, obtiveram-se 30 artigos não repetidos, com título alinhado e com reconhecimento científico. Desses 30 artigos, 29 estavam disponíveis na íntegra, mas dois estavam desalinhados com o tema. Assim, 27 artigos foram selecionados para compor o Portfólio Bibliográfico (PB) final. Após a identificação dos autores profícuos na área, foram incorporados ao PB final mais três artigos. Nesse sentido, o PB final ficou composto por 30 artigos. Esses artigos encontram-se na seção de Referências, com numeração sequencial de 1 a 30 entre [ ] ao final.

\subsection{Procedimentos para análise de dados.}

A análise dos dados com base na leitura dos 30 artigos do PB possibilitará a operacionalização das etapas (ii) análise bibliométrica, (iii) mapa da literatura, e (iv) perguntas como sugestões de agenda de pesquisa e evolução na investigação do tema.

A análise bibliométrica é a segunda etapa do ProKnow-C e consiste em identificar características sobre o tema da pesquisa dentre os artigos do PB, neste trabalho sobre avaliação de desempenho de smart home. Neste tópico, é apresentada a bibliometria básica que ocorre com base em variáveis textuais, sendo possível aferir a contagem de ocorrência dessas variáveis sem a necessidade da interpretação do pesquisador (THIEL; ENSSLIN; ENSSLIN, 2017). A análise bibliométrica nesse estudo apresenta o banco de autores e é a base para identificação de três períodos temporais distinto sobre smart home.

Com base no conhecimento gerado pela leitura e reflexão dos estudos do PB, constata-se que as variáveis referentes ao conteúdo abordado pela avaliação de desempenho de smart home estão relacionadas a abordagens, definições e características de smart home que é sintetizado e apresentado por meio de um mapa da literatura. A Figura 3 apresenta o mapa geral evidenciando o(s) estudo(s) que lhe deu(eram) origem. Os desdobramentos e explicações são apresentados na seção de resultados. 


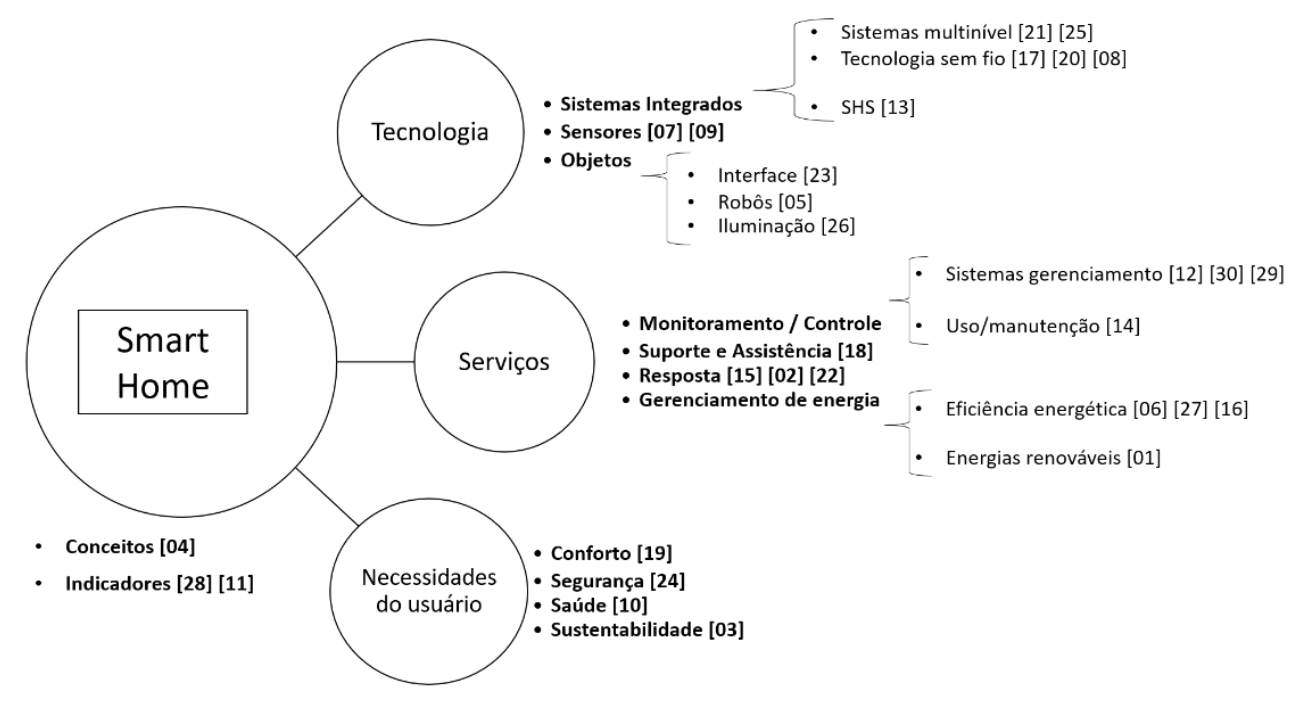

Figura 3 - Mapa da literatura - smart home

\section{Referencial teórico.}

A análise bibliométrica permitiu elaborar o referencial teórico junto a análise de conteúdo do PB. Assim, este tópico está dividido em uma análise sobre a evolução dos estudos sobre a smart home e como estes estudos estão conectadas as teorias do sistema de avaliação de desempenho.

\subsection{Smart home.}

O PB é composto por 30 artigos que foram publicados entre os anos de 2005 a 2019. Com base nesses artigos, observa-se uma evolução em três momentos: 2005 a 2009; 2010 a 2014; e 2015 a 2019. Em cada um desses momentos, algumas características se destacam por serem discutidas em mais de um artigo, ou seja, autores diferentes discutiram a mesma característica em um mesmo intervalo de tempo. Com base nessas características deu-se o nome de cada momento da evolução do assunto (Figura 4). No primeiro momento (de 2005 a 2009), ficou evidente a discussão em torno da sustentabilidade por meio de smart home. O segundo momento (2010 a 2014) incorporou três aspectos nas definições de smart home: pessoas, produtos e processos. No terceiro momento (2015 a 2019), observou-se que smart home está gerando cada vez mais ambientes dinâmicos a serem desenvolvidos. 


\section{SMART HOME}

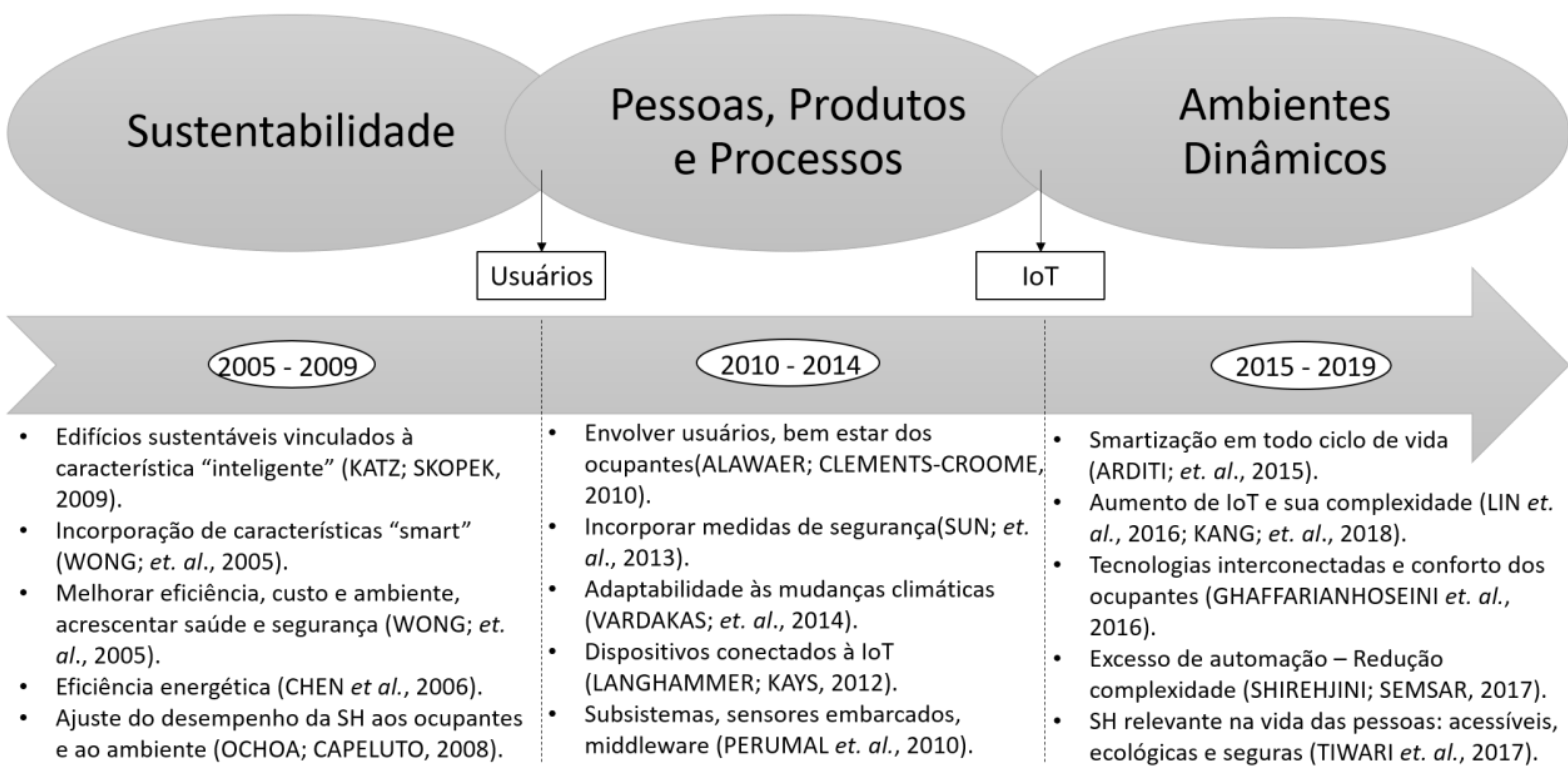

Figura 4 - Evolução do tema smart home ao longo dos anos, com base no PB

\subsection{Sustentabilidade de smart home (2005 a 2009).}

A palavra 'inteligente' foi usada pela primeira vez para descrever edifícios nos Estados Unidos no início dos anos 1980 (WONG; LI; WANG, 2005). Por meio do avanço das tecnologias, principalmente das tecnologias de informação e comunicação, as características smart começaram a surgir, a partir do século XXI, nos estudos e no mercado de construção civil (OCHOA; CAPELUTO, 2008). Katz e Skopek (2009) afirmam que, nas décadas de 1990 e 2000, houve um debate considerável sobre o conceito de edifício 'inteligente', e a impressão final que ficou desses esforços é que um edifício desse tipo não pode ser apenas uma definição, pois existe uma multiplicidade de áreas envolvidas. Inserido nesse contexto de discussão de smart home por várias áreas diferentes, por volta de 2008, observou-se um interesse crescente por parte dos arquitetos e empreendedores em incluir inteligência em edifícios, como uma maneira de alcançar prédios com eficiência energética que cumpram códigos de energia rigorosos e metas nacionais de redução de emissões perigosas (OCHOA; CAPELUTO, 2008). Alguns autores, então, usam definições de smart home com foco na abordagem de sustentabilidade para nortear seus estudos sobre eficiência energética em edifícios (CHEN et al., 2006). Estudos que definem indicadores de desempenho também têm usado essa abordagem de sustentabilidade (WONG; LI; LAI, 2008). Além de estudos que focam questões mais específicas de smart home, como o estudo de Ochoa e Capeluto (2008) que analisa as fachadas inteligentes como apoio à eficiência energética de prédios. Contudo, nesse primeiro momento da evolução sobre smart home, ainda há discussão em torno de uma definição sobre o tema. As primeiras definições de construção inteligente focaram quase inteiramente o aspecto da tecnologia e não sugeriram a interação do usuário, mas essa definição tem sido criticada por muitos pesquisadores e, posteriormente, vários autores estenderam a definição de edifício inteligente e incorporaram a 'capacidade de aprendizado' e a necessidade de 'ajuste de desempenho de sua ocupação e do ambiente' (WONG; LI; WANG, 2005). Observa-se que esse momento da evolução traz aspectos dos primeiros trabalhos sobre edifícios inteligentes, como eficiência e custo, e busca aumentar a eficiência desses aspectos além de acrescentar outros como saúde, segurança e meio ambiente, sendo este último amplamente discutido sob a abordagem da sustentabilidade. A inserção do foco no usuário de smart home é iniciada nesse primeiro momento da evolução e continua aumentando sua discussão no próximo momento temporal. 


\subsection{Pessoas, produtos e processos de smart home (2010 a 2014).}

No sentido de buscar uma definição para smart home, nesse segundo momento da evolução, observa-se que pesquisadores passaram a adotar conceitos que envolviam pessoas, produtos e processos, como no trabalho de Alawaer e Clements-Croome (2010). As pessoas passam a ser fundamentais no desenvolvimento de smart home, onde há necessidade de envolver o usuário em relação aos sistemas de automação residencial e melhorar interfaces para promover a interação entre usuários, valores sociais e ambientais e a smart home (ALAWAER; CLEMENTS-CROOME, 2010). O foco nas pessoas permanece presente na abordagem de processos de smart home, como a implantação de segurança (SUN et al., 2013) e adaptação dos sistemas de smart home às mudanças climáticas (VARDAKAS; ZORBA; VERIKOUKIS, 2014). Os produtos inseridos no contexto de smart home estão relacionados com os sensors e os objetos conectados a IoT (LANGHAMMER; KAYS, 2012) que desenvolvem, em paralelo, os sistemas e subsistemas da automação residencial (PERUMAL et al., 2010). Essa abordagem tecnológica foi usada para desenvolver tecnologia escalável de automação residencial e smart home, por meio do uso da internet (SUN et al., 2013). Isso é uma tendência pela interoperabilidade de sistemas inteligentes em construções inteligentes, onde existem trabalhos que buscam soluções inteligentes como a inteligência artificial (PERUMAL et al., 2010). Apesar dessas tendências, de fato, não há um padrão para os sistemas de automação residencial, os estudos diferem em suas características e apresentam vantagens e desvantagens específicas (LANGHAMMER; KAYS, 2012). Trabalhos com foco nos subsistemas de edifícios inteligentes cresceram devido à combinação de sistemas embarcados de baixo custo e alto desempenho, mais o surgimento de infraestrutura de comunicação de alta capacidade, mais internet (PERUMAL et al., 2010). Mesmo com baixo custo e alto desempenho dos sistemas de automação residencial, ainda não há maior difusão de smart home na prática (LANGHAMMER; KAYS, 2012), mas observa-se o aumento da importância de ambientes inteligentes com smart home (ARNDT et al., 2013).

\subsection{Ambiente Dinâmico (2015 a 2019).}

O ambiente que a smart home proporciona tem se tornado dinâmico e envolve aspectos amplos como a tecnologia, os serviços e os usuários. Para gerar esse ambiente dinâmico é necessário que as características smart sejam incorporadas em todas as fases do ciclo de vida de um edifício (ARDITI; MANGANO; DE MARCO, 2015). Esse aspecto da construção leva a um aumento do uso das tecnologias IoT e da quantidade de objetos conectados à IoT aumentando, assim, a complexidade dos sistemas inteligentes (LIN et al., 2016; ORSINO et al., 2016; DUMANLI et al., 2017; SHIREHJINI; SEMSAR, 2017; SONG et al., 2017; KANG; LIN; ZHANG, 2018). Esse fato é caracterizado por vários estudos, como o de Fahad, Khan e Rajarajan (2015) que apresenta o uso da telemedicina em smart home, permitindo o monitoramento contínuo de pessoas que moram sozinhas. Outro estudo analisa a localização sem fio como foco da IoT (LIN et al., 2016). Dumanli et al. (2017) citam os avanços na tecnologia de detecção como soluções para a saúde moderna e tecnologias vestíveis para monitoramento da saúde e bem-estar do usuário de smart home. Esses estudos buscam desenvolver tecnologias interconectadas e conforto dos ocupantes, além da sustentabilidade (GHAFFARIANHOSEINI et al., 2016). Apesar de a sustentabilidade ter sido uma abordagem mais presente nas discussões do primeiro momento da evolução dessa análise, ela continua nos estudos posteriores, como na preocupação com a eficiência energética das tecnologias sem fio, apresentada por Orsino et al. (2016). O mesmo ocorre com a manutenção da preocupação com as características do segundo momento, como percebe-se no conceito de edifício inteligente utilizado por Arditi, Mangano e De Marco (2015) que contém aspectos de custos energéticos. Ou seja, apesar dos esforços voltados para a tecnologia, o usuário permanece nos estudos de smart home, fato também apresentando no trabalho de desenvolvimento de uma interface adequada para aumentar a confiança do usuário de smart home (SHIREHJINI; SEMSAR, 2017). Diante do cenário de evolução e difusão rápida de tecnologias voltadas para o ambiente de smart home (GHAYVAT; MUKHOPADHYAY; GUI, 2016), alguns autores afirmam que ocorre, nesse momento, 
um excesso de automação gerando alguns problemas como perda de controle, complexidade do ambiente e falta de interfaces de usuário apropriadas para dispositivos cotidianos inteligentes (SHIREHJINI; SEMSAR, 2017), sendo necessária a redução da complexidade gerada desse excesso (GUNAWAN et al., 2018). Vários pesquisadores e desenvolvedores vislumbram, projetam e desenvolvem aplicativos para transformar ambientes físicos em espaços inteligentes e melhorar o uso de smart home pelo usuário, facilitando sua ampla implementação (GUNAWAN et al., 2018). Assim, smart home pode se tornar relevante na vida das pessoas de forma acessível, ecológica e segura (TIWARI; SEWAIWAR; CHUNG, 2017).

\subsection{Smart home e o sistema de avaliação de desempenho.}

Com o objetivo de compreender o tema à luz da área de avaliação de desempenho faz-se necessário explicitar as noções centrais desta área de conhecimento.

O Sistema Avaliação de Desempenho (Performance Evaluation System) contempla dois subsistemas, o subsistema de mensuração de desempenho e o subsistema de gerenciamento de desempenho (LEBAS, 1995; MELNYK et al., 2013) podendo também ser denominado por Sistema de Mensuração e Gerenciamento de Desempenho (PMMS - Performance Measurement and Management System). Essa abordagem holística da avaliação de desempenho sustenta a noção de que esses dois subsistemas são complementares (LEBAS, 1995; ENSSLIN et al., 2013; MELNYK et al., 2013). A mensuração serve de suporte para o gerenciamento que necessita das informações e diagnóstico para orientar as ações a serem planejadas e tomadas.

Com base na análise dos artigos do PB constata-se o alinhamento do conteúdo dos estudos com as funções dos dois subsistemas de avaliação de desempenho. A Figura 5 resume esse alinhamento. E na sequência, detalha-se esse alinhamento primeiro apresentando as noções de $\mathrm{AD}$ suportada pelos teóricos da área e na sequência os estudos do PB.

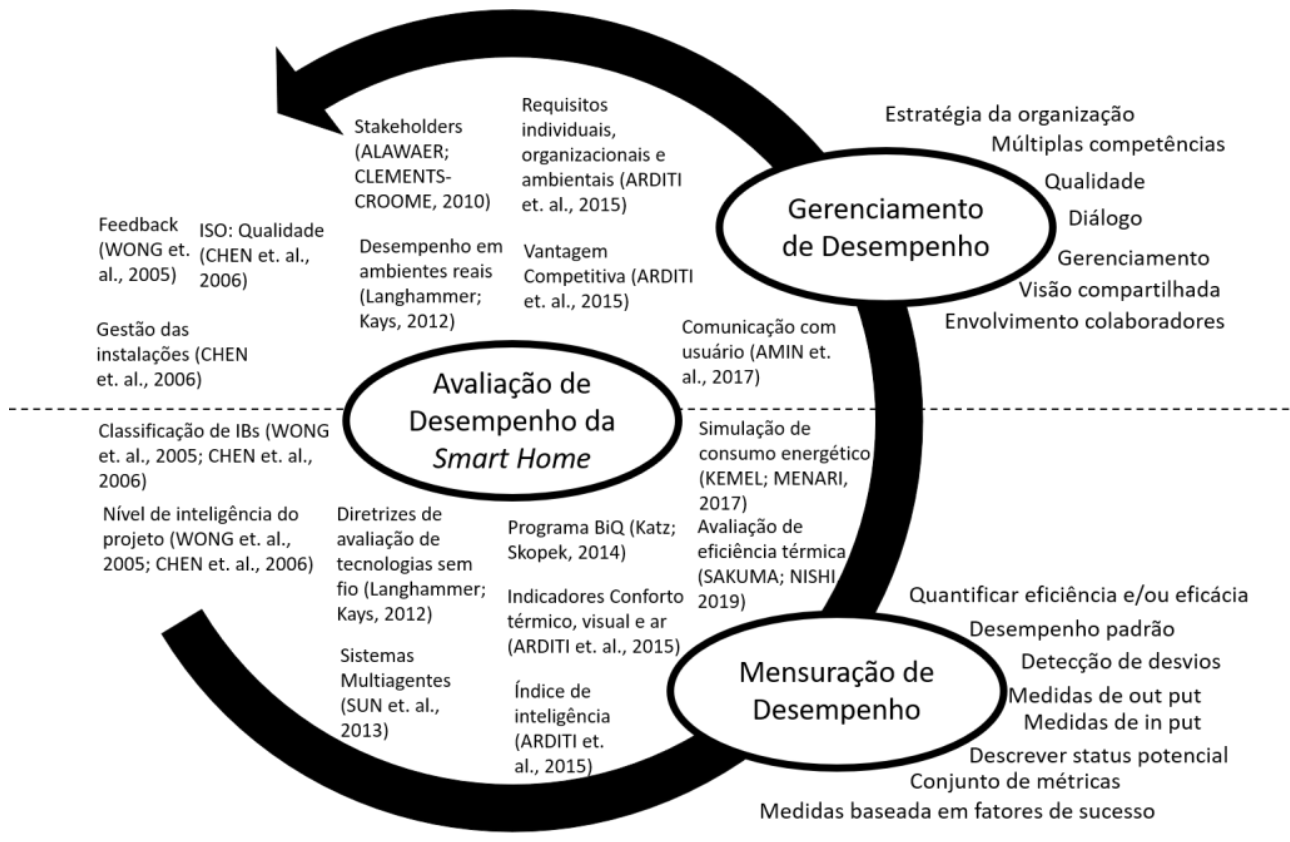

Figura 5 - Alinhamento do tema smart home com os subsistemas de avaliação de desempenho

Definir um conjunto de métricas, determinar os níveis de referência (desempenho mínimos e padrão/meta) e quantificar a eficiência e/ou eficácia da ação são características do subsistema de 
mensuração de desempenho (NEELY; GREGORY; PLATTS, 1995; ENSSLIN; DUTRA; ENSSLIN, 2000; MELNYK et al., 2013). Estudos sobre avaliação de desempenho de smart home apresentam essas características como um estudo sobre a avaliação de eficiência térmica de smart home (SAKUMA; NISHI, 2019); o uso do Programa BiQ como referência para o desenvolvimento de um processo de mensuração (KATZ; SKOPEK, 2009) e o uso de um sistema multiagente composto por um conjunto de métricas para mensuração do desempenho smart home (SUN et al., 2013). Medidas baseadas em fatores críticos/de sucesso, que descrevem um status potencial/status quo, de detecção de desvios, de output e input são medidas do processo de mensuração de desempenho (LEBAS, 1995; NEELY; GREGORY; PLATTS, 1995; ENSSLIN; DUTRA; ENSSLIN, 2000). O sistema de classificação existe para ranquear os prédios inteligentes com base em medidas de inteligência e de sustentabilidade (CHEN et al., 2006), considerados fatores de sucesso no mercado de smart home. Esse sistema de classificação é feito para avaliar prédios existentes e prédios a construir, ou seja, a classificação é feita na fase de projeto (WONG; LI; WANG, 2005) permitindo criar uma seleção dos melhores potenciais prédios inteligentes. O índice de inteligência apresentado no trabalho de Arditi, Mangano e De Marco (2015) é uma medida de output no processo de mensuração de desempenho. Nesse mesmo estudo, os indicadores de conforto térmico, visual e ar são feitos por meio da temperatura, nível de iluminação e concentração de CO2 (ARDITI; MANGANO; DE MARCO, 2015). A simulação é outra ferramenta usada para avaliação de smart home, como no caso em que a simulação foi usada para avaliar o consumo energético de uma residência a fim de detectar possíveis desvios do consumo esperado pelos usuários (KEMEL; MEMARI; BEPAT, 2017).

O gerenciamento de desempenho de smart home pode ser representado pelo uso da AD como vantagem competitiva para as construtoras (ARDITI; MANGANO; DE MARCO, 2015), evidenciando o uso da estratégia organizacional na AD (MELNYK et al., 2013). Além dessa característica, o gerenciamento de desempenho pode ser identificado por meio da preocupação com o uso de múltiplas competências, do diálogo, da qualidade, do gerenciamento, da visão compartilhada e do envolvimento com colaboradores (LEBAS, 1995). No campo de smart home, o feedback (WONG; LI; WANG, 2005) e o gerenciamento das instalações (CHEN et al., 2006) foram preocupações da AD nos primeiros estudos sobre o tema. Nesse período inicial, o uso dos termos de qualidade por meio da ISO foi feito para nortear a gestão de manutenção dos prédios inteligentes (CHEN et al., 2006). Posteriormente, a visão compartilhada do gerenciamento de desempenho foi desenvolvida por meio dos stakeholders que auxiliavam na determinação de indicadores e sua relevância (ALAWAER; CLEMENTS-CROOME, 2010). Além dos stakeholders, de forma mais pontual, os usuários de smart home são envolvidos no gerenciamento de desempenho por meio da sua participação direta em ambientes reais monitorados pelos sistemas inteligentes, permitindo uma avaliação de ambientes reais para apoio aos decisores (LANGHAMMER; KAYS, 2012). Nos últimos estudos, foram observadas as preocupações com as múltiplas competências quando os decisores usam em conjunto para as ferramentas de AD de smart home requisitos individuais, organizacionais e ambientais (ARDITI; MANGANO; DE MARCO, 2015). A tendência observada nos últimos estudos em buscar um foco nos usuários e proprietários de smart home é observado por meio do desenvolvimento de sistemas de comunicação entre os processos de avaliação e o usuário (AMIN et al., 2017), permitindo o diálogo entre os envolvidos no gerenciamento de desempenho. 


\subsection{Análise Bibliométrica.}

O portfólio bibliográfico é composto por 30 artigos, sendo 27 artigos empíricos e 3 artigos teóricos. Dos 27 artigos empíricos, 16 utilizam os indicadores para mensuração de AD, e 11 artigos utilizam algumas ferramentas.

O Banco de Autores (BA) final, atualizado após a definição do PB, é composto por 101 autores. Do total de autores, apenas dois apresentam mais de uma publicação no PB: Clements-Croome e Li, possuindo cada um, dois artigos no PB. Quando realizada a análise das referências dos artigos do PB, esses dois autores reaparecem em destaque com mais outros dois autores, Wang e Berns, conforme Figura 6.

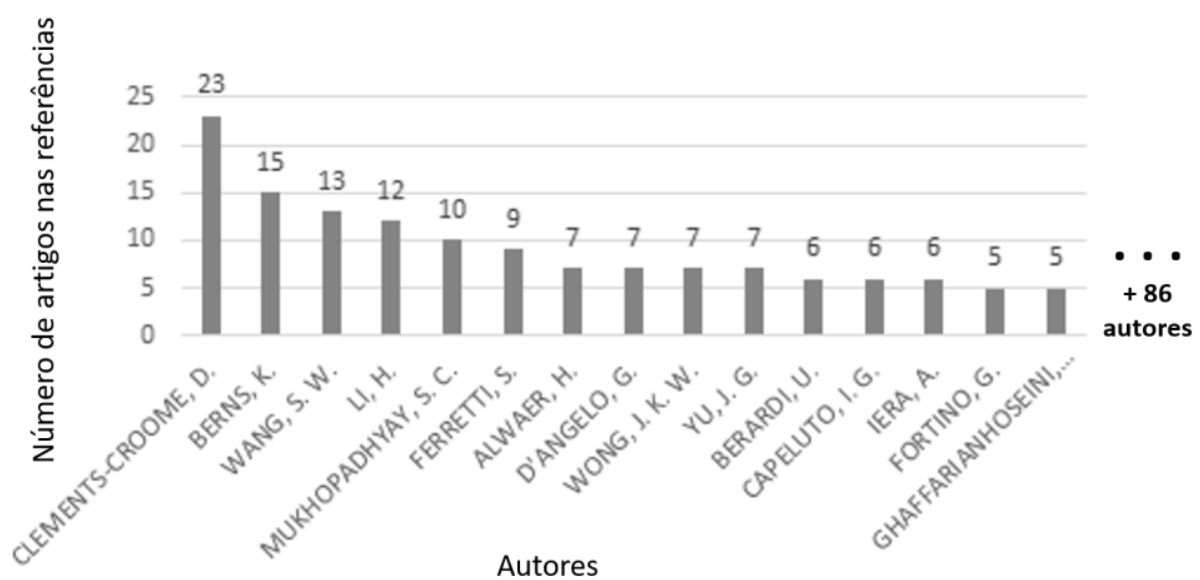

Figura 6 - Quantidade de artigos nas referências por autor

Foi identificado que Berns, apesar dos 15 artigos encontrados nas referências, não é autor com trajetória na área de pesquisa. Ele apresenta uma trajetória mais específica e relacionada à área de robótica que possui ligações com a área de smart home, mas não é o tema desta pesquisa. Assim, observando as trajetórias dos demais autores, foi possível identificar que os autores profícuos na área são Clements-Croome, Wang e Li. A avaliação de desempenho voltada para energia e sustentabilidade em edifícios inteligentes são algumas linhas de pesquisa que Clements-Croome e Wang possuem em comum. Li possui publicação junto com Clements-Croome e, também, com Wang.

Derek John Clements-Croome é professor emérito na Escola de Engenharia e Gestão da Construção, na Universidade de Reading, Inglaterra. É formado em Física, em 1964, pela Universidade de Aston, Inglaterra. Obteve o título de Mestre em Física Vibracional e Acústica, em 1966, pela Universidade de London, também na Inglaterra. O professor é Doutor em Engenharia de Construção e Meio Ambiente, título obtido em 1978 pela Universidade de Loughborough, novamente na Inglaterra. Trabalhou na indústria de projeto e construção de edifícios antes de entrar para a Academia. Nessa carreira, passou pelas Universidades de Loughborough e de Bath e, hoje, está na Universidade de Reading, todas na Inglaterra. Além desta última universidade, Clements-Croome é professor visitante em universidades da China e Finlândia. Ele pesquisa, escreve e ministra palestras sobre obtenção e gerenciamento de ambientes saudáveis e sustentáveis em edifícios de todos os tipos. Exerce consultoria 
nesse mesmo tema. Possui mais de 400 publicações, desde a década de 1960, e cinco livros. Entre os dez artigos mais citados, dois estão no PB selecionado. São muitos os autores parceiros nas publicações, entre os cinco com maior quantidade de publicação juntos, um autor está entre os mais referenciados no PB selecionado, Heng Li. Fundou e, hoje edita, o Intelligent Buildings International Journal. Faz parte de várias comissões nacionais e internacionais que debatem o seu tema de pesquisa.

Shengwei Wang é professor da Universidade Politécnica de Hong Kong, China. Obteve o grau de Bacharelado em Engenharia, em 1983, e o grau de Mestre, em 1986, na área de Refrigeração e ArCondicionado, ambos pela Universidade de Ciência e Tecnologia de Huazhong (HUST), China. O seu PhD foi obtido, em 1993, na área de HVAC (Heating, Ventilation and Air Conditioning) e Automação Predial pela Universidade de Liège, Bélgica. Além de ser professor da Universidade Politécnica de Hong Kong é também professor convidado, professor adjunto e professor visitante da Universidade de Xi'an Jiaotong, Universidade de Xangai Jiaotong, Universidade de Hunan, Universidade de Ciência e Tecnologia Huazhong, Universidade de Tecnologia do Sul da China, Universidade de Zhejiang, Hangzhou, Universidade do Sudeste, Universidade de Donghua, Universidade de Tecnologia de Dalian e Universidade de Maryland, todas na China. Suas pesquisas são desenvolvidas na área de construção de edifícios inteligentes e energia. Como pesquisador, ele se esforça na obtenção de fundos e recursos para pesquisa e desenvolvimento. Nesse sentido, já obteve mais de 30 fundos aprovados e um total de mais de 18 milhões de dólares de Hong Kong (aproximadamente 9,5 milhões de reais). Participou ativamente de vários programas de pesquisa da Agência Internacional de Energia e do programa Conservação de Energia para Sistemas Construtivos e Comunitários. Publicou mais de 240 artigos, sendo que o seu artigo mais citado (Intelligent building research: a review) faz parte do PB selecionado. Esse artigo foi escrito em parceria com outros dois autores, sendo um deles um dos mais referenciados no PB selecionado, Heng Li. Wang publicou dois livros e foi coautor em outros quatro livros. Complementando, Wang é editor associado do HVAC \& Research, o periódico acadêmico da Sociedade Americana de Engenheiros de Aquecimento, Refrigeração e Ar-Condicionado (ASHRAE)

Heng Li é professor da Universidade Politécnica de Hong Kong, China. Iniciou sua carreira acadêmica na Universidade de Tongji, em 1987, China. Foi pesquisador e ministrou palestras na Universidade de Sydney, na James Cook University e na Monash University, todas na Austrália, antes de ingressar na Universidade Politécnica de Hong Kong. Suas áreas principais de ensino são: construção digital e inteligente; tecnologia da informação em construção; gerenciamento de construção; e tecnologia de construção. Durante o período em que esteve na Austrália, Heng trabalhou com empresas de projeto e construção de engenharia e prestou serviços de consultoria a organizações privadas e governamentais na Austrália, em Hong Kong e na China. O tema central de suas pesquisas está relacionado à aplicação e transferências inovadoras de tecnologias da informação da construção. Publicou mais de 300 artigos, sendo que o seu segundo artigo mais citado (Intelligent building research: a review) faz parte do $\mathrm{PB}$ selecionado e, também publicou dois livros na área e inúmeros trabalhos em conferências. Um dos principais autores com quem publica em conjunto é Shengwei Wang, que faz parte do banco de autores do PB selecionado e publicou dois livros na área e inúmeros trabalhos em conferências.

\subsection{Mapa da literatura.}

Analisando o conteúdo dos estudos percebeu-se que o tema smart home se desdobra em três elementos abrangentes: a tecnologia envolvida com smart home, os serviços que podem ser oferecidos por smart home e as necessidades dos usuários para obterem as principais funcionalidades de smart home. Na forma mais geral, três artigos apresentaram estudos teóricos, dois com foco nos conceitos de smart home e um com foco nos indicadores de desempenho de smart home. Todos os demais artigos (27 artigos) são estudos empíricos e estão distribuídos nos três elementos já citados. A tecnologia que envolve smart home está subdivida em sistemas integrados, sensores e objetos. Os sistemas integrados representam os estudos sobre sistemas multiníveis, tecnologia sem fio e sistemas inteligentes de smart 
home. Os objetos são os chamados devices que, nesse $\mathrm{PB}$, estão representados por interfaces, robôs e iluminação. O segundo elemento abrangente é representado pelos serviços que smart home pode oferecer. Esses serviços são o monitoramento e controle de todos os componentes de smart home de forma interligada; o suporte e assistência para apoio à tomada de decisão dos usuários, proprietários e construtores; a resposta que é o feedback de informações geradas por smart home; e o gerenciamento de energia de smart home. O monitoramento e controle de smart home, nesse PB, é representado pelos sistemas de gerenciamento em todo o ciclo de vida do prédio e pelos estudos com foco na fase de uso e manutenção do prédio. O gerenciamento de energia é bem focado na eficiência energética (consumo de energia principalmente) e um estudo com foco na questão das energias renováveis. A necessidade dos usuários tem sido o foco e é bastante discutido na literatura de forma geral, mas, nesse $\mathrm{PB}$, apenas os aspectos de conforto, segurança, saúde e sustentabilidade apresentaram estudos empíricos.

A síntese desse panorama sobre o tema é apresentada no mapa da literatura (Figura 7) e seu detalhamento nos mapas que se seguem.

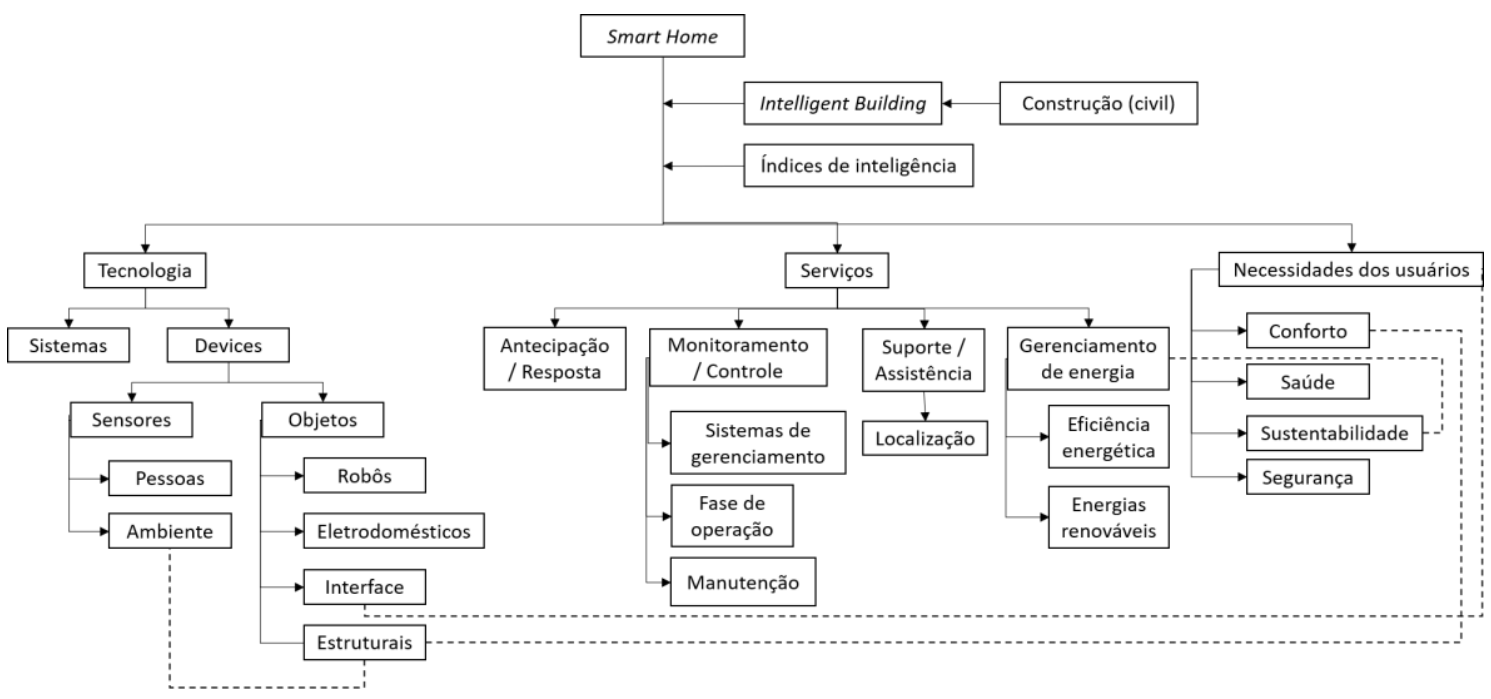

Figura 7 - Abordagens de smart home e suas relações.

A Figura 7 representa o mapa da literatura com as especificações, descritas anteriormente, e as relações que existem entre as abordagens de smart home, estabelecidas em três categorias por meio de um estudo recente de revisão sistemática da literatura sobre as smart homes (MARIKYAN; PAPAGIANNIDIS; ALAMANOS, 2019). A abordagem tecnológica de smart home, por meio de objetos inteligentes, permite criar interfaces conforme as necessidades dos usuários e gerar conforto térmico e de iluminação aos usuários por meio de estruturas residenciais inteligentes. $\mathrm{O}$ ambiente tecnológico por meio de sensores busca atender à demanda dos usuários, proprietários e construtores. Dentre essas demandas, há também o viés da sustentabilidade que tem gerado um diferencial como vantagem competitiva no mercado da construção inteligente. Essa abordagem da necessidade do usuário está relacionada com o gerenciamento de energia que é um desdobramento da abordagem de serviços. Apesar da identificação de três abordagens macros de smart home na literatura, os seus desdobramentos se relacionam e mostram que o conceito de smart home é baseado na integração de suas características.

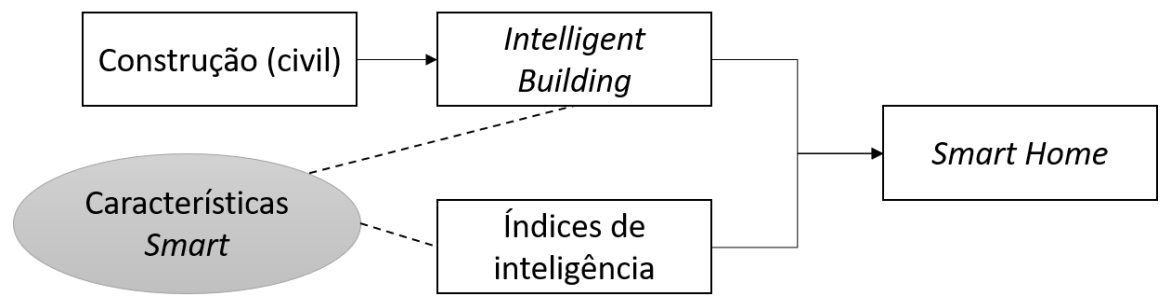

Figura 8 - Origem e construção do conceito de smart home 
O conceito de smart home evoluiu do conceito intelligence building que se originou da área da construção civil (Figura 8). Com o aumento da automação nos edifícios, surge uma linha de pesquisa que envolve os prédios inteligentes, residenciais e comerciais. Em algumas linhas de estudos, a inteligência dos prédios está associada à sustentabilidade e, por consequência, usar essas características como uma vantagem competitiva. No mercado, algumas instituições buscam apresentar essa vantagem por meio de comparação com outras construções. Assim, surgiram os índices de inteligência como forma de avaliar o desempenho dos prédios inteligentes. As características de inteligência foram obtendo um foco nas residências e, dessa forma, estudos voltados para smart home foram publicados apresentando conceitos com abordagens diferentes. Alguns conceitos buscam ser abrangentes, outros apresentam uma abordagem como as encontradas nos artigos do PB: tecnologia, serviços e necessidades dos usuários.

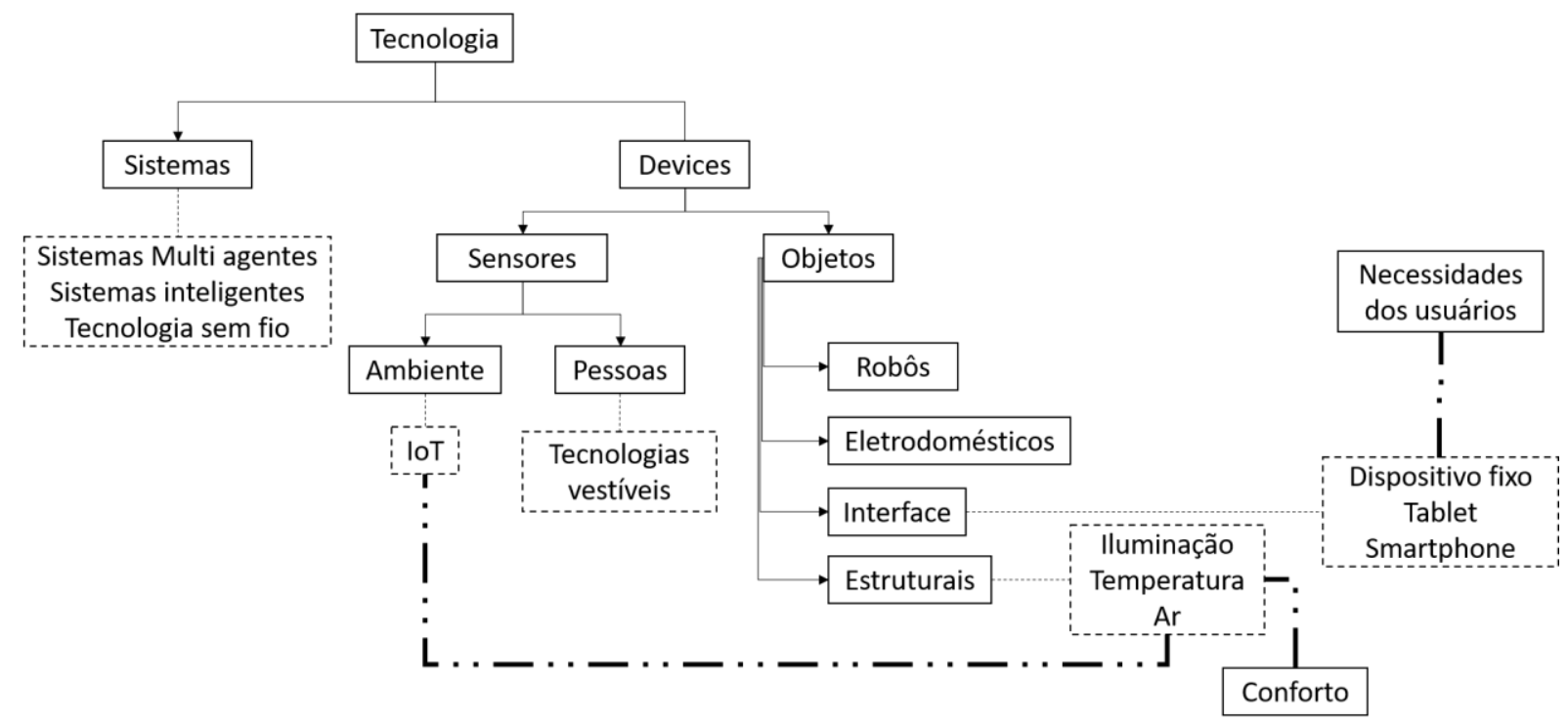

Figura 9 - Abordagem tecnológica de smart home

A abordagem tecnológica de smart home engloba os sistemas e os itens físicos (devices) de uma casa (Figura 9). Os sistemas discutidos na literatura reportam o desempenho dos sistemas inteligentes e esse tipo de sistema envolve vários agentes (sensores, aparelhos domésticos, usuários etc.). A partir dos aparelhos domésticos inteligentes, é possível coletar dados para alimentar um sistema inteligente com foco na redução de energia (ORSINO et al., 2016). A tecnologia sem fio domina os sistemas inteligentes ao permitirem o desenvolvimento de aplicações da IoT na automação residencial (DEL CARPIO et.al., 2017). Os estudos sobre devices de smart home apresentam uma discussão sobre a melhor forma de integrar os sensores. Estes podem ser fixos em residências ou em móveis, como as tecnologias vestíveis (DUMANLI et al., 2017). Dentre esses estudos, observa-se que a internet das coisas (IoT) atua como suporte no desempenho de smart home. Os objetos de smart home englobam aparelhos utilizados nas atividades de rotinas dos usuários, como eletrodomésticos, robôs (como os de limpeza), celulares, notebooks, aparelhos de ar-condicionado, dentre outros (ARNDT et al., 2013). Todos os objetos devem ter algum tipo de conectividade para integrar smart home. 


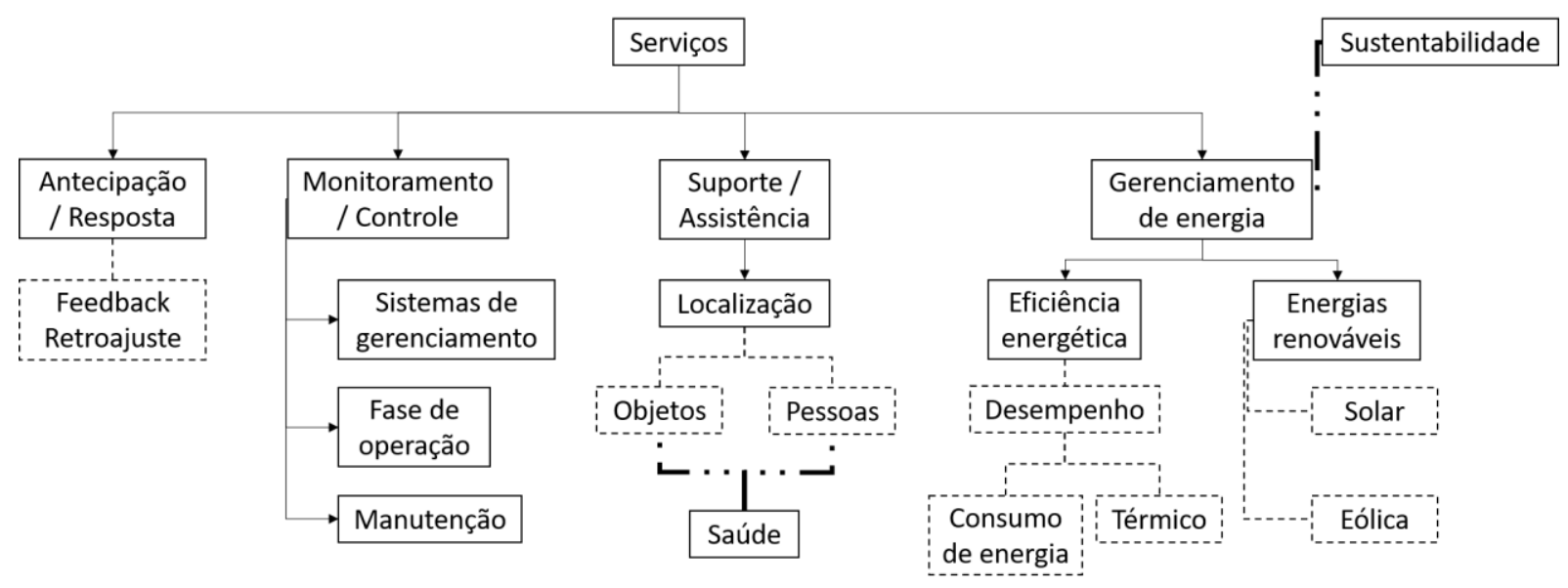

Figura 10 - Abordagem de serviços de smart home

Os serviços de smart home vão além do monitoramento e controle da residência e envolve suporte e assistência, feedback e o gerenciamento de energia, este último é voltado para a sustentabilidade (Figura 10). O objetivo do feedback é oferecer informações sobre a residência para o usuário poder tomar decisões. Essa antecipação e resposta dos sistemas de gerenciamento é possível devido ao monitoramento que ocorre durante o uso da residência; os sistemas de monitoramento promovem a eficiência das informações utilizadas, permitindo ao usuário manter em boas condições o edifício (LIN et. al., 2016; KANG; LIN; ZHANG, 2018). No PB, os serviços de suporte e assistência discutem como os sensores na casa e nas pessoas podem auxiliar o usuário na questão de sua saúde, ou seja, smart home permite um monitoramento remoto da saúde dos moradores. Por meio de reconhecimento das atividades dos usuários, que envolve os sensores de localização, é possível identificar se um usuário sofreu uma queda (FAHAD, KHAN; RAJARAJAN; 2015). O gerenciamento de energia é o foco da sustentabilidade em smart home, com desenvolvimento de modelos de decisão para avaliação do ciclo de vida útil de um prédio inteligente, em relação a sua eficiência energética (CHEN et. al., 2006). Busca a eficiência energética e o uso de energias renováveis (AHMED; KANG; KIM, 2015). A análise do desempenho energético é observada no PB com foco no consumo de energia (VARDAKAS; ZORBA; VERIKOUKIS, 2014) e no conforto térmico (KEMEL; MEMARI; BEPAT, 2017; SAKUMA; NISHI, 2019).

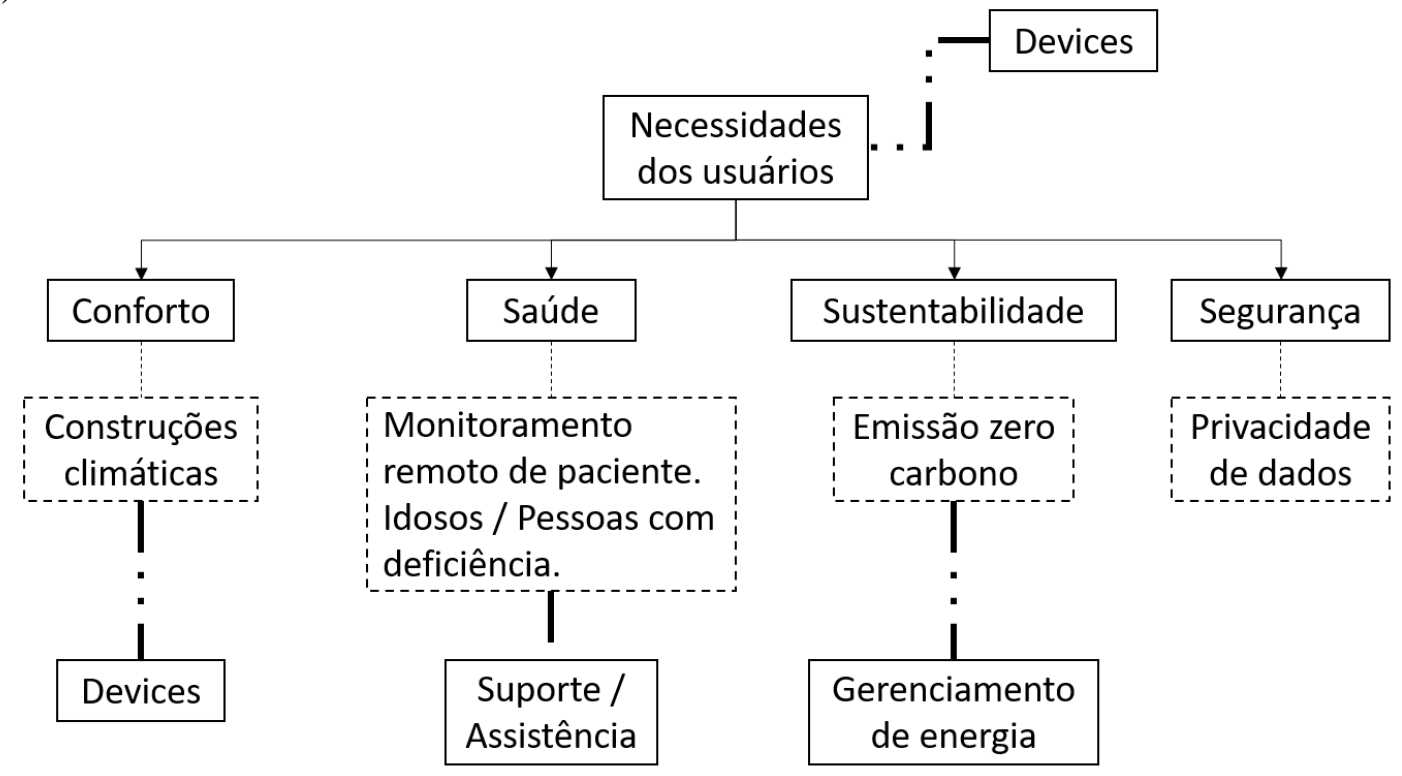

Figura 11 - Abordagem das necessidades de usuários de smart home 
O conforto, o bem-estar, a consciência ambiental e a segurança são as necessidades dos usuários discutidas nos artigos do PB (Figura 11). Um dos objetivos de smart home é atender de forma inteligente às demandas de seus moradores por meio das abordagens tecnológicas e dos serviços que os construtores buscam desenvolver. Uma dessas demandas é a segurança contra invasão de privacidade e, entre os estudos do portfólio, alguns protocolos de comunicação foram desenvolvidos para analisar a segurança dos dados e avaliar o desempenho do sistema para garantir a privacidade dos dados dos usuários (SONG et al., 2017). Outra demanda está relacionada com a saúde dos usuários e os sistemas de suporte e assistência, da abordagem tecnológica, permite à telemedicina o monitoramento remoto de pacientes e, aos familiares, o monitoramento de idosos e pessoas com alguma deficiência (FAHAD, KHAN; RAJARAJAN; 2015). A consciência ambiental pode influenciar na tomada de decisão de um usuário de smart home, ou seja, a possibilidade de se ter uma residência sustentável é uma das demandas dos usuários. $\mathrm{O}$ gerenciamento de energia, da abordagem de serviços, possiibilita que uma smart home consuma menos energia e gere menos poluição por carbono na atmosfera, oferendo um lado sustentável para o uso de smart home (AMIN et al., 2017). Antes da fase do uso da smart home há a construção da residência e, nessa fase, deve-se considerar, entre diversos fatores, materiais adequados a serem utilizados para promover as construções climáticas, que são residências que oferecem o conforto térmico junto com a eficiência energética (OCHOA; CAPELUTO, 2008).

\section{Considerações finais.}

Os conceitos e definições de smart home se originaram dos estudos de prédios inteligentes, por volta do início dos anos 2000, indicando este ser um tema emergente. A evolução dos estudos na área sob a luz da avaliação de desempenho não se apresenta de forma linear, indicando estudos que estão focados na padronização de métodos de avaliação de desempenho em paralelo a estudos focados em demonstrar a importância de criar um sistema de avaliação para cada caso em específico. Mas é possível identificar características, nesses estudos, de gerenciamento de desempenho e de mensuração de desempenho.

Este trabalho permitiu identificar as características dos estudos na área de avaliação de desempenho de smart home, por meio de um fragmento da literatura. Para tal foi selecionado um PB composto por 30 artigos, publicados entre os anos de 2005 a 2019.

Em linhas gerais, a análise dos estudos resumidamente evidenciaram: (i) existência de períodos temporais com discussões das características em torno da sustentabilidade (de 2005 a 2009), incrementadas pelos elementos pessoas, produtos e processos (de 2010 a 2014) levando a necessidade de contemplar os ambientes dinâmicos que passaram a emergir (de 2015 a 2019); (ii) existência de alinhamento do conteúdo dos estudos do PB com as funções dos subsistemas mensuração e gerenciamento de avaliação de desempenho; (iii) Clements-Croome, Wang e Li são autores profícuos na área, e (iv) que os estudos de smart home podem ser sintetizados em três abordagens, em termos da tecnologia envolvida, dos serviços que podem ser oferecidos e das necessidades dos usuários para obterem as suas principais funcionalidades. Ainda nesse PB, observou-se a falta de estudos que discutissem e apresentassem métodos para a gestão dos sistemas de avaliação de desempenho. Identifica, assim, uma possibilidade de estudos: Por que não há artigos que não apresentam a gestão dos indicadores? Será uma área promissora de investigação? Será um gargalo nos processos de smart home?

A visão sobre a evolução do tema e para qual direção novos estudos se guiarão foi obtida por meio de um fragmento extraído da literatura com condições específicas de coletas de dados. Essa situação limita o presente estudo. 
AHMED, M. A.; KANG, Y. C.; KIM, Y. C. Communication Network Architectures for Smart-House with Renewable Energy Resources. Energies, v. 8, n. 8, p. 8716-8735, 2015. doi:10.3390/en8088716

ALAWAER, H.; CLEMENTS-CROOME, D. J. Key performance indicators (KPIs) and priority setting in using the multi-attribute approach for assessing sustainable intelligent buildings. Building and Environment, v. 45, n. 4, p. 799-807, 2010. doi: 10.1016/j.buildenv.2009.08.019

AMIN, U.; HOSSAIN, M. J.; LU, J.; FERNANDEZ, E. Performance analysis of an experimental smart building: Expectations and outcomes. Energy, v. 135, p. 740-753, 2017. doi: 10.1016/j.energy.2017.06.149

ARDITI, D.; MANGANO, G.; DE MARCO, A. Assessing the smartness of buildings. Facilities, v. 33, n. 9-10, p. 553-572, 2015. doi: 10.1108/F-10-2013-0076

ARNDT, M.; WILLE, S.; DE SOUZA, L.; REY, V. F.; WEHN, N.; BERNS, K. Performance evaluation of ambient services by combining robotic frameworks and a smart environment platform. Robotics and Autonomous Systems, v. 61, n. 11, p. 1173-1185, 2013. doi: 10.1016/j.robot.2013.04.007

BITITCI, U. S.; GARENGO, P.; DÖRFLER, V.; NUDURUPATI, S. Performance Measurement: Challenges for Tomorrow. International Journal of Management Reviews, v. 14, n. 3, p. 305-327, 2012. doi: 10.1111/j.1468-2370.2011.00318.x

CHEN, Z.; CLEMENTS-CROOME, D.; HONG, J.; LI, H.; XU, Q. A multicriteria lifespan energy efficiency approach to intelligent building assessment. Energy and Buildings, v. 38, n. 5, p. 393-409, 2006. doi: 10.1016/j.enbuild.2005.08.001

D'ANGELO, G.; FERRETTI, S.; GHINI, V. Multi-level simulation of Internet of Things on smart territories. Simulation Modelling Practice and Theory, v. 73, p. 3-21, 2017. doi: 10.1016/j.simpat.2016.10.008

DEL CARPIO, L. F.; DI MARCO, P.; SKILLERMARK, P.; CHIRIKOV, R.; LAGERGREN, K. Comparison of 802.11ah, BLE and 802.15.4 for a Home Automation Use Case. International Journal of Wireless Information Networks, v. 24, n. 3, p. 243-253, 2017. doi: 10.1007/s10776-017-0355-2

DUMANLI, S.; SAYER, L.; MELLIOS, E.; FAFOUTIS, X.; HILTON, G. S.; CRADDOCK, I. J. OffBody Antenna Wireless Performance Evaluation in a Residential Environment. IEEE Transactions on Antennas and Propagation, v. 65, n. 11, p. 6076-6084, 2017. doi: 10.1109/TAP.2017.2748362

DUTRA, A.; RIPOLL-FELIU, V. M.; FILLOL, A. G.; ENSSLIN, S. R.; ENSSLIN, L. The construction of knowledge from the scientific literature about the theme seaport performance evaluation. International Journal of Productivity and Performance Management, v. 64, n. 2, p. 243-269, 2015. doi: 10.1108/IJPPM-01-2014-0015

ENSSLIN, L.; DUTRA, A.; ENSSLIN, S. R. MCDA: A constructivist approach to the management of human resources at a governmental agency. International Transactions in Operational Research, v. 7, n. 1, p. 79-100, 2000. doi: 10.1016/S0969-6016(99)00025-8

ENSSLIN, S.R.; ENSSLIN, L.; BACK, F.; LACERDA, R. T. De O. Improved decision aiding in human resource management: a case using constructivist multi-criteria decision aiding. The International Journal of Productivity and Performance Management, v. 62, p. 735-757, 2013. doi: 10.1108/IJPPM04-2012-0039 
ENSSLIN, L.; ENSSLIN, S. R.; DUTRA, A. PROKNOW-C: um processo para geração de conhecimento e identificação de oportunidades de pesquisa científica. Florianópolis: Universidade Federal de Santa Catarina, 2019. 106f. Apostila da disciplina EPS 6307000 - Avaliação de Desempenho. 2019.

FAHAD, L. G.; KHAN, A.; RAJARAJAN, M. Activity recognition in smart homes with self verification of assignments. Neurocomputing, v. 149, p. 1286-1298, 2015. doi: 10.1016/j.neucom.2014.08.069

FRANCO-SANTOS, M.; LUCIANETTI, L.; BOURNE, M. Contemporary performance measurement systems: A review of their consequences and a framework for research. Management Accounting Research, v. 23, n. 2, p. 79-119, 2012. doi: 10.1016/j.mar.2012.04.001

GHAFFARIANHOSEINI, A.; BERARDI, U.; ALWAER, H.; CHANG, S.; HALAWA, E.; GHAFFARIANHOSEINI, A.; CLEMENTS-CROOME, D. What is an intelligent building? Analysis of recent interpretations from an international perspective. Architectural Science Review, v. 59, n. 5, p. 338-357, 2016. doi: 10.1080/00038628.2015.1079164

GHAYVAT, H.; MUKHOPADHYAY, S. C.; GUI, X. Issues and mitigation of interference, attenuation and direction of arrival in IEEE 802.15.4/ZigBee to wireless sensors and networks based smart building. Measurement: Journal of the International Measurement Confederation, v. 86, p. 209-226, 2016. doi: 10.1016/j.measurement.2016.01.045 [12]

GUNAWAN, T. S.; YALDI, I. R. H.; KARTIWI, M.; MANSOR, H. Performance evaluation of smart home system using internet of things. International Journal of Electrical and Computer Engineering, v. 8, n. 1, p. 400-411, 2018. doi: 10.11591/ijece.v8i1.pp400-411

KANG, K.; LIN, J. R.; ZHANG, J. P. BIM- and IoT-based monitoring framework for building performance management. Journal of Structural Integrity and Maintenance, v. 3, n. 4, p. 254-261, 2018. doi: $10.1080 / 24705314.2018 .1536318$

KATZ, D.; SKOPEK, J. The CABA building intelligence quotient programme. Intelligent Buildings International, v. 1, n. 4, p. 277-295, 2009. doi:10.3763/inbi.2009.SI05

KEMEL, E.; MEMARI, A. M. BEPAT. A platform for building energy assessment in energy smart homes and design optimization. Advances in Energy Research, v. 5, n. 4, p. 321-339, 2017. doi: 10.12989/eri.2017.5.4.321

LACERDA, R. T. De O.; ENSSLIN, L., ENSSLIN, S. R. Uma análise bibliométrica da literatura sobre estratégia e Avaliação de Desempenho. Gestão \& Produção, v.19, n.1, p. 59-78, 2012. doi: $10.1590 /$ S0104-530X2012000100005

LANGHAMMER, N.; KAYS, R. Performance evaluation of wireless home automation networks in indoor scenarios. IEEE Transactions on Smart Grid, v. 3, n. 4, p. 2252-2261, 2012. doi: 10.1109/TSG.2012.2208770

LEBAS, M. Performance measurement and performance management. International Journal of Production Economics, v.41, p. 23-35, 1995. doi: 10.1016/0925-5273(95)00081-X

LIN, K.; CHEN, M.; DENG, J.; HASSAN, M. M.; FORTINO, G. Enhanced Fingerprinting and Trajectory Prediction for IoT Localization in Smart Buildings. IEEE Transactions on Automation Science and Engineering, v. 13, n. 3, p. 1294-1307, 2016. doi: 10.1109/TASE.2016.2543242 
MELNYK, S. A.; BITITCI, U.; PLATTS, K.; TOBIAS, J.; ANDERSEN, B. Is performance measurement and management fit for the future? Management Accounting Research, 2013. doi: 10.1016/j.mar.2013.07.007

NEELY, A.; GREGORY, M.; PLATTS, K. Performance measurement system design: A literature review and research agenda. International Journal of Operations \& Production Management, v. 15, n. 4, p. $80-116$, 1995. doi: $10.1108 / 01443579510083622$

OCHOA, C. E.; CAPELUTO, I. G. Strategic decision-making for intelligent buildings: Comparative impact of passive design strategies and active features in a hot climate. Building and Environment, v. 43, n. 11, p. 1829-1839, 2008. doi: 10.1016/j.buildenv.2007.10.018

ORSINO, A.; ARANITI, G.; MILITANO, L.; ALONSO-ZARATE, J.; MOLINARO, A.; IERA, A. Energy efficient IoT data collection in smart cities exploiting D2D communications. Sensors, v. 16, n. 6, p. 1-18, 2016. doi: doi:10.3390/s16060836

PERUMAL, T.; RAMLI, A. R.; LEONG, C. Y.; SAMSUDIN, K.; MANSOR, S. Middleware for heterogeneous subsystems interoperability in intelligent buildings. Automation in Construction, v. 19, n. 2, p. 160-168, 2010. doi: 10.1016/j.autcon.2009.11.014

SAKUMA, Y.; NISHI, H. Estimation of Building Thermal Performance using Simple Sensors and Air Conditioners. Energies, v. 12, n. 15, p. 1-22, 2019. doi: 10.3390/en12152950

SHIREHJINI, A. A. N.; SEMSAR, A. Human interaction with IoT-based smart environments. Multimedia Tools and Applications, v. 76, n. 11, p. 13343-13365, 2017. doi: 10.1007/s11042-016-36973

SONG, T. Y.; LI, R. N.; MEI, B.; YU, J. G.; XING, X. S.; CHENG, X. Z. A Privacy Preserving Communication Protocol for IoT Applications in Smart Homes. IEEE Internet of Things Journal, v. 4, n. 6, p. 1844-1852, 2017. doi: 10.1109/JIOT.2017.2707489

STAEDELE, A. E.; ENSSLIN, S. R.; FORCELLINI, F. A. Knowledge building about performance evaluation in lean production. Journal of Manufacturing Technology Management, v. 30, n. 5, p. 798820, 2019. doi: 10.1108/JMTM-12-2017-0277

SUN, Q.; YU, W.; KOCHUROV, N.; HAO, Q.; HU, F. A multi-Agent-based intelligent sensor and actuator network design for smart house and home automation. Journal of Sensor and Actuator Networks, v. 2, n. 3, p. 557-588, 2013. doi: 10.3390/jsan2030557

THIEL, G. G.; ENSSLIN, S. R.; ENSSLIN, L. Street Lighting Management and Performance Evaluation: Opportunities and Challenges. Lex Localis - Journal of Local Self-Government, v. 15, n. 2, p. 303-328, 2017. doi: 10.4335/15.2.303-328(2017)

TIWARI, S. V.; SEWAIWAR, A.; CHUNG, Y. H. Smart home multi-device bidirectional visible light communication. Photonic Network Communications, v. 33, n. 1, p. 52-59, 2017. doi: 10.1007/s11107015-0600-5

VARDAKAS, J. S.; ZORBA, N.; VERIKOUKIS, C. V. Scheduling policies for two-state smart-home appliances in dynamic electricity pricing environments. Energy, v. 69, p. 455-469, 2014. doi: $10.1016 /$ j.energy.2014.03.037

WONG, J. K. W.; LI, H.; WANG, S. W. Intelligent building research: a review. Automation in Construction, v. 14, n. 1, p. 143-159, 2005. doi: 10.1016/j.autcon.2004.06.001 
WONG, J.; LI, H.; LAI, J. Evaluating the system intelligence of the intelligent building systems - Part 1. Automation in Construction, 2008. doi: 10.1016/j.autcon.2007.06.002

WONG, J.; LI, H.; LAI, J. Evaluating the system intelligence of the intelligent building systems - Part 2. Automation in Construction, 2008. doi:10.1016/j.autcon.2007.06.003 